\title{
End-of-Life Care Practice in Dying Patients after Enforcement of Act on Decisions on Life-Sustaining Treatment For Patients in Hospice and Palliative Care or at the End of Life: A Single Center Experience
}

\author{
Sol Jin, M.D., Jehun Kim, M.D.*, Jin Young Lee, M.D. ${ }^{\dagger}$ Taek Yong Ko, M.D. ${ }^{\dagger}$ and Gyu Man Oh, M.D. \\ Departments of Internal medicine, "Pulmonology, ${ }^{\dagger}$ Infectious disease, \\ ${ }^{\ddagger}$ Thoracic and Cardiovascular Surgery, Kosin University Gospel Hospital, Busan, Korea
}

Purpose: The Act on Hospice and Palliative Care and Decisions on Life-Sustaining Treatment for Patients at the End of Life came into force in February 2018 in Korea. This study reviews the practices of end-of-life care for patients who withdrew or withheld lifesustaining treatment at a tertiary care hospital, addresses the limitations of the law, and discusses necessary steps to promote patient-centered self-determination. Methods: We retrospectively analyzed the medical records of patients who died after agreeing to withhold lifesustaining treatment in 2018 at our university hospital. The cause of death, the intensity of end-of-life care, and other characteristics were reviewed and statistically analyzed. Results: Of a total of 334 patients, 231 (69\%) died from cancer. The decision to stop life-sustaining treatment was made by family members for 178 patients overall (53.3\%) and for 101 (43.7\%) cancer patients, regardless of the patient's wishes. When the patient decided to stop lifesustaining treatment, the time from the authorization to withhold life-sustaining treatment to death was longer than when the decision was made by family members $(28.7 \pm 41.3$ vs $10.5 \pm 23.2$ days, $\mathrm{P}<0.001)$. Conclusion: In many cases, the decision to discontinue lifesustaining treatment was made by the family, not by the patient. In order to protect human dignity based on the patients' self-determination, it is necessary for patients to understand their disease based on careful explanations from physicians. Ongoing survey-based research will be necessary in the future.

Key Words: Advance care planning, Terminal care, Korea
Received March 5, 2020

Revised May 12, 2020

Accepted May 13, 2020
Correspondence to

Jehun Kim

ORCID: https://orcid.org/0000-0002-

2594-0256

E-mail: libertier@gmail.com

\section{INTRODUCTION}

\section{Background}

Due to developments in modern medicine, the average life expectancy is increasing worldwide, and ethical and legal problems have accordingly arisen with regard to the process of deciding upon and administering proper life-sustaining treatment. Laws have been established and implemented in several countries to help patients facing imminent death to discontinue life-sustaining treatments that are considered medically meaningless and to maintain their dignity. In Taiwan and the United States, legislation has been passed to ensure that patients make choices regarding life-sustaining treatment, such as physician 
orders for life-sustaining treatment (POLST), natural death laws, and hospice laws; notable legal measures include the Austrian Patient Pre-Decision Act, Singapore's Medical Advance Decision Act, and the French Patient Rights and Endof-Life Act [1]. In Korea, discussions about how to decide on life-sustaining treatment have continued since the Boramae incident in 1997, and official discussions about the suspension of meaningless life-sustaining treatment started as a result of Madam Kim's case in 2008. In February 2016, the Act on Hospice and Palliative Care and Decisions on Life-Sustaining Treatment for Patients at the End of Life (hereinafter referred to as the Act on Decisions on Life-Sustaining Treatment was enacted, resulting in the systematization of life-sustaining treatment decisions, and the act fully came into force on February 4, 2018 after a 2-year preparation period [2].

The Act on Decisions on Life-Sustaining Treatment allows "patients at the end of life" to decide on their own whether to receive life-sustaining treatment, protects patients' self- determination, and guarantees patients' best interests by legally protecting their decisions. Life-sustaining treatment includes cardiopulmonary resuscitation (CPR), ventilator care, hemodialysis, and chemotherapy. Informed consent for withdrawal of life-sustaining treatment is provided in one of three ways: first, the patient clearly expresses in an advance directive or life-sustaining treatment plan that he or she does not want life-sustaining treatment; second, if the patient is unconscious, two of the patient's family members provide consistent statements regarding the patient's intentions; and third, through consensus of the patient's entire family [3].

In February 2018, a system for making life-sustaining treatment decisions was implemented, but no detailed reports have yet investigated the real-world use of life-sustaining treatment. It is necessary to understand the actual conditions in the medical field for the life-sustaining treatment decisions system to be appropriately used, and it is thought that doing so will help achieve the type of life-sustaining treatment that medical staff, patients, and guardians want.

\section{Purpose}

This study was conducted to investigate the actual conditions and to address relevant limitations after the implementation of the Act on Decisions on Life-Sustaining Treatment for patients at a single medical institution. In this study evaluating the limitations of the Act on Decisions on Life-Sustaining Treatment and ways to address those limitations, we investigated the informed consent forms completed within a year after the Act on Decision on Life-Sustaining Treatment was implemented, and compared and analyzed the diseases encompassed by the law, the types of informed consent, differences between cancer and non-cancer patients, and whether the patient's intentions were reflected when the consent form was completed. Based on this analysis, this study discusses the supplemental steps necessary to promote patient-centered self-determination in lifesustaining treatment decisions.

\section{METHODS}

\section{Subjects}

This study conducted a retrospective analysis of the medical records of patients who had provided written informed consent for life-sustaining treatment decisions from February 1, 2018 to August 1, 2018 at a tertiary university hospital in Busan.

All patients who provided informed consent for life-sustaining treatment decisions were included, with the exception of patients who made this decision on an outpatient basis and were not hospitalized.

\section{Data collection}

From patients' medical records, information was extracted on sex, age, where the life-sustaining treatment plan was written, whether or not the patient died, the length of the hospital stay, when the life-sustaining treatment document was written, the period from the completion of the document to death, the type of the document that was written, the content of the document, underlying diseases that led to death, and special life-sustaining treatments such as inotropics, CPR, mechanical ventilation, high-flow nasal cannula therapy, and dialysis. Patients were divided into terminal patients and patients at the end stage of life based on the main diagnosis on the death certificate. Terminal patients included those with cancer, AIDS, chronic obstructive pulmonary disease, and cirrhosis. Other patients at the end stage of life were those with dis- 
Table 1. Patients Characteristics ( $N=334)$.

\begin{tabular}{|c|c|}
\hline Variables & $\mathrm{n}(\%)$ or Mean $\pm \mathrm{SD}$ \\
\hline \multicolumn{2}{|l|}{ Sex } \\
\hline Male & $213(63.8)$ \\
\hline Female & $121(36.2)$ \\
\hline Age (yr) & $67.8 \pm 12.3$ \\
\hline \multicolumn{2}{|l|}{ Place where consent for withholding life-sustaining treatment was provided } \\
\hline General ward & $183(54.8)$ \\
\hline Intensive care unit & $104(31.1)$ \\
\hline Emergency room & $47(14.1)$ \\
\hline \multicolumn{2}{|l|}{ Survival or location of death } \\
\hline Survival & $27(8.1)$ \\
\hline Death at our hospital & $261(78.1)$ \\
\hline Death at other place & $46(13.8)$ \\
\hline \multicolumn{2}{|l|}{ Duration of hospitalization (days) } \\
\hline Admission to consent for withholding of life-sustaining treatment & $13.4 \pm 19.5$ \\
\hline Consent for withholding life-sustaining treatment to death & $17.0 \pm 32.0$ \\
\hline \multicolumn{2}{|l|}{ Form of agreement to withhold life-sustaining treatment } \\
\hline POLST & $87(26.0)$ \\
\hline Advance directives & $28(8.4)$ \\
\hline Patient's decision confirmation (statement made by the patient's family) & $41(12.3)$ \\
\hline Confirmation of the decision by the patient's family & $178(53.3)$ \\
\hline \multicolumn{2}{|l|}{ Types of patients } \\
\hline End stage of life patients & $87(26.0)$ \\
\hline Cardiovascular disease & $28(8.4)$ \\
\hline Disease of the respiratory system & $19(5.7)$ \\
\hline Disease of the central nervous system & $15(4.5)$ \\
\hline Kidney disease & $11(3.3)$ \\
\hline Infectious disease & $6(1.8)$ \\
\hline Liver disease & $3(0.9)$ \\
\hline Gastrointestinal disease & $3(0.9)$ \\
\hline Endocrine disease & $2(0.6)$ \\
\hline Terminal patients & $247(74.0)$ \\
\hline Cancer & $231(69.2)$ \\
\hline Liver cirrhosis & $9(2.7)$ \\
\hline COPD & $7(2.1)$ \\
\hline \multicolumn{2}{|c|}{ Special life-sustaining treatments mentioned in the consent form (multiple responses) } \\
\hline Cardiac resuscitation & $333(99.7)$ \\
\hline Intubation and ventilator care & $267(79.9)$ \\
\hline Hemodialysis & $275(82.3)$ \\
\hline Chemotherapy & $292(87.4)$ \\
\hline \multicolumn{2}{|c|}{ Intensive end of life care before the provision of consent for withholding life-sustaining treatment } \\
\hline Inotropics & $136(40.7)$ \\
\hline Intubation and ventilator care & $79(23.7)$ \\
\hline HFNC & $50(15.0)$ \\
\hline Hemodialysis & $44(13.2)$ \\
\hline Cardiac resuscitation & $21(6.3)$ \\
\hline
\end{tabular}

Values are presented as mean \pm standard deviation or number (\%).

POLST: physician orders for life-sustaining treatment, CNS: central nerve system, AIDS: acquired immunodeficiency syndrome, COPD: chronic obstructive pulmonary disease, HFNC: high-flow nasal cannula. 
eases of the central nervous system, diseases of the respiratory system, cardiovascular disease, infectious disease, kidney disease, or liver disease. This study was conducted with the approval of the institution's Institutional Review Board (KUGHIRB-2019-02-014).

\section{Content of the informed consent for withdrawal of life-sustaining treatment}

When the informed consent for withdrawal of life-sustaining treatment was written, the patient (terminal or at the end stage of life) declared his or her intention to withhold or withdraw life-saving medical treatment through the life-sustaining treatment plan. Furthermore, all citizens over the age of 19 have been encouraged to write an advance directive regarding life-sustaining treatment and hospice care in case they reach the end stage of life. If there is no advance directive or lifesustaining treatment plan when the decision to withhold or withdraw life-sustaining treatment must be made, a patient confirmation form (a statement from the patient's family) is prepared by the guardian to describe the patient's intentions regarding life-sustaining treatment. Alternatively, the statement can be completed with the agreement of all of the patient's family members. The issues addressed in the informed consent form included whether to continue or discontinue $\mathrm{CPR}$, hemodialysis, chemotherapy, or ventilator care.

\section{Data analysis}

Patients' characteristics were analyzed according to the cause of death, whether the patient's intentions were reflected in the informed consent for withdrawal of life-sustaining treatment, and the degree of implementation of special life-sustaining treatment before consent was provided to withdraw the lifesustaining treatment.

SPSS version 24 (IBM Corp, Armonk, NY, USA) was used for statistical analysis. The Mann-Whitney $U$ test was used to evaluate statistical significance in comparative analyses of continuous variables, and the chi-square test and the Fisher exact test were used for nominal variables.

\section{RESULTS}

\section{General characteristics of subjects}

In total, 409 patients provided consent for life-sustaining treatment decisions at $\mathrm{K}$ University Hospital in the 7-month period from February 2018 to August 2018, while 65 patients were excluded because they filled out the forms on an outpatient basis and were not hospitalized. Thus, 334 patients were included in the final analysis, of whom $26.0 \%$ were at the end stage of life, and $74.0 \%$ were terminal patients. Malignant tumors were present in $69.2 \%$ of the patients. The patient wrote the life-sustaining treatment plan in $26.0 \%$ of cases and an advance directive in $8.4 \%$ of cases, while a patient's intention statement was prepared by family members in $12.3 \%$ of cases and a joint statement from the patient's guardian and family members was provided in $53.3 \%$ of cases. In most cases, written confirmation from the patient's guardian and family members was prepared (Table 1).

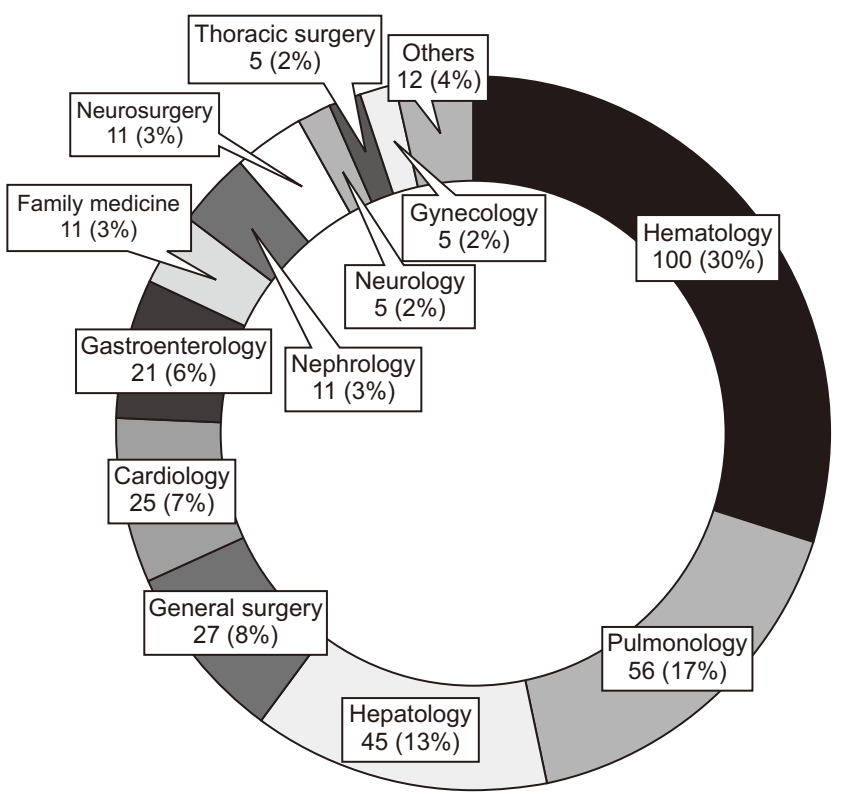

Figure 1. Departments responsible for the care of patients who provided consent for withholding life-sustaining treatment permit.

Others: endocrinology, 3; infectious diseases 2; urology, 1; pediatrics, 1; rehabilitation medicine, 1; orthopedics, 1. 


\section{Specialties of the physicians treating patients who provided informed consent for withdrawal of life-sustaining treatment}

In an analysis of the treating physicians according to the patients' underlying disease, it was found that $79.3 \%$ of $\mathrm{pa}^{-}$ tients were treated by physicians in the Department of Internal Medicine, including $29.9 \%$ who were treated by hematologists, $16.8 \%$ who were treated by pulmonologists, and $13.5 \%$ who were treated by hepatologists. Furthermore, $15.2 \%$ of patients were treated by surgeons (Figure 1).

\section{Differences between cancer and non-cancer patients}

Patients with malignant tumors (cancer patients) and other diseases (non-cancer patients) were compared and analyzed. There were 231 cancer patients and 103 non-cancer patients. The mean age of the cancer patients was 65.2 years $( \pm 11.3)$, while that of the non-cancer patients was 73.6 years $( \pm 12.6)$. Of the cancer patients who provided written consent to discontinue life-sustaining treatment, $70.1 \%$ did so in the general ward and $29.9 \%$ did so in the intensive care unit. In contrast, of the non-cancer patients, $58.4 \%$ completed the consent form in the intensive care unit, whereas only $41.7 \%$ did so in the general ward $(\mathrm{P}<0.01)$. Among the cancer patients, the average period from hospitalization to completion of the informed consent for withdrawal of life-sustaining treatment was 14.6 days $( \pm 18.5$ ), and the average period from completion of the informed consent for withdrawal of life-sustaining treatment to death was 18.2 days $( \pm 31.5)$. Among the non-cancer patients, the corresponding intervals were 10.6 days $( \pm 21.2)$ and 14.0 days ( \pm 33.2 ), respectively. Although this difference was not statistically significant, it is noteworthy that both of these intervals were shorter among non-cancer patients (Table 2).

For cancer patients, $44.2 \%$ of the completed documents were written by the patient, while $54.8 \%$ were written by a guardian. In contrast, for non-cancer patients, only $12.7 \%$ were written by the patient, while the remaining $87.4 \%$ were written by the guardian. This was a significant difference $(\mathrm{P}<0.01)$.

All cancer patients refused CPR, and ventilator care was rejected by $89.6 \%$ of patients, hemodialysis by $90.0 \%$, and chemotherapy by $84.8 \%$. Of the non-cancer patients, $99.0 \%$ refused CPR, 58.3\% refused ventilator care, $65.0 \%$ refused hemodialysis, and $93.2 \%$ refused chemotherapy, showing that non-cancer patients refused special life-sustaining treatments at a lower overall rate, except for chemotherapy.

The life-sustaining treatment administered prior to the patients providing informed consent for withdrawal of life-sustaining treatment was inotropics in $31.2 \%$ of cases, ventilator care in $11.3 \%$, high-flow nasal cannula therapy in $13 \%$, hemodialysis in $6.9 \%$, and CPR in $1.3 \%$ for cancer patients. For non-cancer patients, the corresponding rates were $62.1 \%$ for inotropics, $51.5 \%$ for ventilator care, $19.4 \%$ for a high-flow nasal cannula therapy, $27.2 \%$ for hemodialysis, and $17.5 \%$ for CPR. Non-cancer patients showed a higher overall rate of life-sustaining treatment than cancer patients. One or more special life-sustaining treatments were received by $37.2 \%$ of cancer patients, but by $78.6 \%$ non-cancer patients, showing a significant difference $(\mathrm{P}<0.01)$.

\section{Comparison of patient's decision-making when preparing informed consent for withdrawal of life-sustaining treatment}

Cases in which the patient provided informed consent for withdrawal of life-sustaining treatment were compared to those in which a guardian or family members provided consent. The average age of patients who provided written consent themselves (patient group) was 63.9 years $( \pm 10.4$ ), while that of patients for whom a guardian or family members provided written consent (guardian group) was 69.9 years ( \pm 12.8). The patients in the guardian group were significantly older $(\mathrm{P}<0.01)$ (Table 3). The consent form was filled out in the general ward in $86.1 \%$ of cases in the patient group, in the intensive care unit in $7.8 \%$ of cases, and in the emergency room in $6.1 \%$ of cases. In the guardian group, the corresponding percentages were $38.4 \%$ for the general ward, $43.4 \%$ for the intensive care unit, and $18.3 \%$ for the emergency room, reflecting a significant difference from the patient group ( $\mathrm{P}$ $<0.01$ ). The average period from hospitalization to the provision of written consent to withdraw life-sustaining treatment was 11.7 days $( \pm 14.2)$ in the patient group and 14.2 days $( \pm 21.7)$ in the guardian group, which was not statistically significant $(\mathrm{P}=0.204)$. However, the average period to death after completion of the consent form for the withdrawal of 
Table 2. Comparative Analysis according to Cause of Death ( $\mathrm{N}=334)$.

\begin{tabular}{|c|c|c|c|}
\hline \multirow{2}{*}{ Variables } & Cancer (N=231) & Non-cancer $(\mathrm{N}=103)$ & \multirow{2}{*}{ P-value } \\
\hline & $\mathrm{n}(\%)$ or Mean $\pm \mathrm{SD}$ & $\mathrm{n}(\%)$ or Mean $\pm \mathrm{SD}$ & \\
\hline Sex & & & 0.77 \\
\hline Male & $149(64.5)$ & $64(62.1)$ & \\
\hline Female & $82(35.5)$ & $39(37.9)$ & \\
\hline Age (yr) & $65.2 \pm 11.3$ & $73.6 \pm 12.6$ & \\
\hline $\begin{array}{l}\text { Place where consent for withholding life-sustaining } \\
\text { treatment was provided }\end{array}$ & & & $<0.001$ \\
\hline General ward & $162(70.1)$ & $21(20.4)$ & \\
\hline Intensive care unit & $44(19.0)$ & $60(58.3)$ & \\
\hline Emergency room & $25(10.8)$ & $22(21.4)$ & \\
\hline Survival or location of death & & & 0.047 \\
\hline Survival & $13(5.6)$ & $14(13.6)$ & \\
\hline Death at our hospital & $185(80.1)$ & $76(73.8)$ & \\
\hline Death at other place & $33(14.3)$ & $13(12.6)$ & \\
\hline \multicolumn{4}{|l|}{ Duration of hospitalization (days) } \\
\hline Admission to consent for withholding of life-sustaining treatment & $14.6 \pm 18.5$ & $10.6 \pm 21.2$ & 0.081 \\
\hline Consent for withholding life-sustaining treatment to death & $18.2 \pm 31.5$ & $14.0 \pm 33.2$ & 0.306 \\
\hline Form of agreement to withhold life-sustaining treatment & & & $<0.001$ \\
\hline POLST & $79(34.2)$ & $8(7.8)$ & \\
\hline Advance Directives & $23(10.0)$ & $5(4.9)$ & \\
\hline Patient's decision confirmation (statement made by the patient's family) & $28(12.1)$ & $13(12.6)$ & \\
\hline Confirmation of the decision by the patient's family & $101(43.7)$ & $77(74.8)$ & \\
\hline \multicolumn{4}{|l|}{$\begin{array}{l}\text { Special life-sustaining treatments mentioned in the } \\
\text { consent form (multiple responses) }\end{array}$} \\
\hline Cardiac resuscitation & $231(100.0)$ & $102(99.0)$ & 0.678 \\
\hline Intubation and ventilator care & $207(89.6)$ & $60(58.3)$ & $<0.001$ \\
\hline Hemodialysis & $208(90.0)$ & $67(65.0)$ & $<0.001$ \\
\hline Chemotherapy & $196(84.8)$ & $103(100.0)$ & $<0.001$ \\
\hline \multicolumn{4}{|l|}{$\begin{array}{l}\text { Intensive end of life care before the provision of consent for withholding } \\
\text { life-sustaining treatment }\end{array}$} \\
\hline Inotropics & $159(68.8)$ & $39(37.9)$ & $<0.001$ \\
\hline Intubation and ventilator care & $205(88.7)$ & $50(48.5)$ & $<0.001$ \\
\hline HFNC & $201(87.0)$ & $83(80.6)$ & 0.175 \\
\hline Hemodialysis & $215(93.1)$ & $75(72.8)$ & $<0.001$ \\
\hline Cardiac resuscitation & $228(98.7)$ & $85(82.5)$ & $<0.001$ \\
\hline \multicolumn{4}{|l|}{$\begin{array}{l}\text { Intensive end of life care before provision of consent for } \\
\text { withholding life-sustaining treatment }\end{array}$} \\
\hline Done & $86(37.2)$ & $81(78.6)$ & $<0.001$ \\
\hline
\end{tabular}

Values are presented as mean standard deviation or number (\%).

POLST: physician orders for life-sustaining treatment, HFNC: high flow nasal cannula.

life-sustaining treatment was 28.7 days $( \pm 41.3)$ in the patient group and 10.5 days $( \pm 23.2)$ in the guardian group, demonstrating that there was a significant difference according to who made the decision $(\mathrm{P}<0.01)$. In the patient group, $7.8 \%$ of patients were in the end stage of life and $92.2 \%$ were terminal patients, whereas the corresponding proportions were $35.6 \%$ and $64.4 \%$, respectively, in the guardian group (P
$<0.01)$. Patients were more likely to refuse all types of lifesustaining treatment than guardians. In particular, in the patient group, ventilator care and hemodialysis were refused in $96.5 \%$ of cases, but only in $71.2 \%$ and $74.9 \%$ of cases in the guardian group, respectively. This was a significant difference $(\mathrm{P}<0.01)$. Life-sustaining treatment was administered prior to the written consent to discontinue the life-sustaining medical 
Table 3. Comparison of Various Factors according to Whether the Patient or the Patient's Family Made the Decision to Provide Consent to Withdraw Life-Sustaining Treatment ( $\mathrm{N}=334)$.

\begin{tabular}{|c|c|c|c|}
\hline \multirow[t]{2}{*}{ Variables } & $\begin{array}{l}\text { Patient decision } \\
\quad(\mathrm{N}=115)\end{array}$ & $\begin{array}{l}\text { Family decision } \\
(\mathrm{N}=219)\end{array}$ & \multirow[t]{2}{*}{ P-value } \\
\hline & $\mathrm{n}(\%)$ or Mean $\pm \mathrm{SD}$ & $n(\%)$ or Mean $\pm S D$ & \\
\hline Sex & & & 0.246 \\
\hline Male & $68(59.1)$ & $145(66.2)$ & \\
\hline Female & $47(40.9)$ & $74(33.8)$ & \\
\hline Age (yr) & $63.9 \pm 10.4$ & $69.9 \pm 12.8$ & $<0.001$ \\
\hline $\begin{array}{l}\text { Place where consent for withholding life-sustaining } \\
\text { treatment was provided }\end{array}$ & & & $<0.001$ \\
\hline General ward & $99(86.1)$ & $84(38.4)$ & \\
\hline Intensive care unit & $9(7.8)$ & $95(43.4)$ & \\
\hline Emergency room & $7(6.1)$ & $40(18.3)$ & \\
\hline Survival or location of death & & & 0.061 \\
\hline Survival & $6(5.2)$ & $21(9.6)$ & \\
\hline Death at our hospital & $87(75.7)$ & $174(79.5)$ & \\
\hline Death at other place & $22(19.1)$ & $24(11.1)$ & \\
\hline \multicolumn{4}{|l|}{ Duration of hospitalization (days) } \\
\hline Admission to consent for withholding of life-sustaining treatment & $11.7 \pm 14.2$ & $14.2 \pm 21.7$ & 0.204 \\
\hline Consent for withholding life-sustaining treatment to death & $28.7 \pm 41.3$ & $10.5 \pm 23.2$ & $<0.001$ \\
\hline Types of patients & & & $<0.001$ \\
\hline End stage of life patients & $9(7.8)$ & $78(35.6)$ & \\
\hline Terminal patients & $106(92.2)$ & $141(64.4)$ & \\
\hline \multicolumn{4}{|l|}{$\begin{array}{l}\text { Special life-sustaining treatments mentioned } \\
\text { in the consent form (multiple responses) }\end{array}$} \\
\hline Cardiac resuscitation & $115(100)$ & $218(99.5)$ & 1 \\
\hline Intubation and ventilator care & $111(96.5)$ & $156(71.2)$ & $<0.001$ \\
\hline Hemodialysis & $111(96.5)$ & $164(74.9)$ & $<0.001$ \\
\hline Chemotherapy & $102(88.7)$ & $190(86.8)$ & 0.739 \\
\hline \multicolumn{4}{|l|}{$\begin{array}{l}\text { Intensive end of life care before provision of consent for } \\
\text { withholding life-sustaining treatment }\end{array}$} \\
\hline Done & $21(18.3)$ & $146(66.7)$ & $<0.001$ \\
\hline
\end{tabular}

Values are presented as mean \pm standard deviation or number (\%).

treatment in $18.3 \%$ of cases in the patient group, but in $66.7 \%$ of cases in the guardian group $(\mathrm{P}<0.01)$.

\section{DISCUSSION}

The purpose of this study was to determine which patients used the Act on Decisions on Life-Sustaining Treatment in actual medical care, and how and when they did so, by analyzing their clinical characteristics and features of the written life-sustaining treatment decisions made by patients who have decided to withdraw life-sustaining treatment at a single tertiary hospital after the implementation of the system for life-sustaining treatment decisions. The most important as- pect of the current system of making life-sustaining treatment decisions is that it provides a framework for withdrawing life-sustaining treatment based on the patient's intentions, as expressed by the patient himself or herself at the time of the decision. However, if the patient's consciousness is impaired, his or her intention often cannot be determined. Therefore, decisions were often made based on confirmation by the patient's guardian and/or family members. However, it is difficult to be sure that the patient's intent is accurately expressed by family members. During the study period, it was only possible to discontinue life-sustaining medical treatment with the consent of the patient's spouse and all lineal ancestors and descendants. Therefore, family members who did not want to extend the 
life-sustaining treatment due to delays in the process of $\mathrm{de}^{-}$ termining the patient's intention may have said that the patient did not want life-sustaining treatment regardless of the patient's actual intention. In this regard, it is important to make decisions about life-sustaining treatment when the patient's consciousness is clear in order to ensure patient-centered self-determination. The concept of life-sustaining treatment decisions should be addressed in national policy discussions, so that it will be possible to develop a culture of expressing one's intention regarding life-sustaining care by talking with family members in general, or even for healthy adults to write advance directives stating their intent regarding life-sustaining treatment. In addition, when it becomes unlikely that a patient's disease will be cured, it will be necessary for the medical staff to explain lifesustaining treatments in advance and help the patient to make his or her own decisions.

Cancer patients were more likely than non-cancer patients to complete informed consent forms for withdrawal of lifesustaining treatment themselves, even though their average age was lower than that of non-cancer patients (Table 2). Cancer patients are often aware that their disease is likely to worsen, so they often do not want to receive life-sustaining treatment. In addition, cancer patients' rate of special lifesustaining treatments, such as intensive care unit treatment, ventilator treatment, hemodialysis, and CPR before completion of the consent form for life-sustaining treatment was also lower than that of non-cancer patients. In a domestic study, Kim et al. [4] compared and analyzed the intensity of end-oflife treatment at a single institution, and the degree of special life-sustaining treatment was found to be significantly lower in cancer patients than in non-cancer patients; furthermore, non-cancer patients provided informed consent to withdraw life-sustaining treatment when death was more imminent [4]. In this study, non-cancer patients had longer intervals from hospitalization to life-sustaining treatment decisions and from the decision to discontinue life-sustaining treatment than cancer patients, but the difference was not statistically significant. This may have been due to the fact that this study was conducted among patients who provided consent to discontinue life-sustaining treatment during hospitalization and excluded outpatients who provided consent, as those patients would be expected to have a relatively long survival time. Nevertheless, the tendency for a shorter interval from obtaining consent to death among cancer patients is presumed to reflect earlier and more frequent consent to discontinue life-sustaining treatment based on the awareness that cancer was incurable, among both patients and their family members [5].

Terminal patients accounted for most of those who completed the agreement to discontinue life-sustaining treatment (92.0\%), and it was found that in $18.3 \%$ of cases, life-sustaining treatment was conducted before the patient provided written consent to discontinue life-sustaining treatment. In contrast, for $35.6 \%$ of patients at the end stage of life, a guardian or family members completed the agreement to discontinue life-sustaining treatment, and the percentage of patients who received special life-sustaining treatment before the discontinuation of life-sustaining treatment was also high (66.7\%). Patients with acute diseases such as cerebrovascular disease and cardiovascular disease were also included among the cases in which a guardian or family members completed the agreement to discontinue life-sustaining treatment. Guardians and family members were less likely than patients to refuse special life-sustaining treatments such as cardiopulmonary resuscitation, ventilator treatment, and hemodialysis. This is thought to reflect the guardians' and family members' anxiety and guilt regarding the decision not to pursue additional treatment $[6,7]$. For this reason, if the patient has difficulty expressing his or her intention, the attending physician should provide detailed explanations of the patient's condition and future prognosis, and respect the wishes of the guardians and family members to help determine the best medical care [8].

Of the 334 patients who completed an informed consent, 115 were able to make their own decisions regarding hospice care, of whom 74 patients agreed to hospice care. All 74 patients were cancer patients and did not want CPR or hemodialysis. It is thought that the attending physician will need to explain hospice care and palliative medicine to patients with the aim of improving terminal patients' quality of life.

Prior to the implementation of the Act on Decisions on LifeSustaining Treatment, do-not-resuscitate (DNR) forms were prepared according to each hospital's guidelines as a way for end-of-life patients to make decisions at the end stage of life to withhold and withdraw life-sustaining treatment. Previous studies have reported that most end-of-life patients in 
Korea had DNR forms completed by their family members immediately before the end of life. In 2018, a single-institution study conducted by Yoon et al. in Korea [5] confirmed that the median interval from completing the DNR agreement until death was 3 days for cancer patients and 2 days for noncancer patients; in contrast, much longer intervals were found in this study, with median intervals from the consent to discontinue life-sustaining treatment to death of 18.2 days and 14 days in cancer and non-cancer patients, respectively. In the cases analyzed in this study, the patient or guardian provided consent to discontinue life-sustaining treatment after receiving a sufficient explanation from the treating physician, and it is thought that these results reflect changes in the overall perceptions of life-sustaining treatment through nationwide public awareness campaigns and education on the suspension of the life-sustaining treatment. Indeed, according to the National Agency for Management of Life-sustaining Treatment, as of April 2020, approximately 40,000 life-sustaining treatment plans and about 610,000 advance directives on life-sustaining treatment had been registered, and the implementation of discontinuation of life-sustaining treatment has also increased monthly; furthermore, as of April 2020, 98,000 people were confirmed to have implemented discontinuation of life-sustaining treatment [9]. It is thought that the number of patients who have completed and implemented agreements to discontinue life-sustaining treatment will increase further.

One of the biggest obstacles after the implementation of the Act on Decisions on Life-Sustaining Treatment in 2018 was the need for all family members of patients to express consent when filling out the consent form for guardians and family members. This requirement made it difficult to complete the consent form if family members had lost contact or if a family member was living abroad. In one case, as many as seven family members were required to finalize the agreement, which posed a significant logistical challenge. In some cases, some of the immediate family members did not know other family members' contact information, or special life-sustaining treatment was required for patients for whom family members' contact information could not be obtained. The unfairness of this has been regularly pointed out, and in March 2019, the legislation was revised to address this issue. From March 28, 2019, the revised form of the Act on Decisions on Life-
Sustaining Treatment made it possible to adjust the scope of the patient's family, expand the range of medical procedures covered, and expand the conditions under which agreements can be written. The scope of the family was narrowed from the spouse and all immediate blood relatives to the spouse and direct descendants, and the duration for which contact with a "missing person" must have been lost for that person to be excluded from these agreements has also been adjusted from 3 years to 1 year from the date of the report. In addition, the medical procedures classified as life-sustaining treatment have been expanded to include in vitro life-sustaining procedures, blood transfusions, and blood pressure-increasing drugs as well as the previous treatments of CPR, ventilator care, hemodialysis, and anti-cancer medications that the doctor in charge believes it necessary to withhold or withdraw. It is expected that these changes will compensate for the shortcomings of the previous legislation.

This study has some limitations. First, it only analyzed patients admitted to a single hospital, and also targeted a subset of patients who were admitted to a tertiary hospital and received active treatment. Because retrospective studies are likely to be affected by sampling bias, a prospective analysis is needed for more patients, including outpatients.

In 2018, the Life-Sustaining Treatment Decisions Act was enacted, and received national publicity through media and advertisements. In comparison to the rates identified in previous studies and actual surveys, the number of drafts of lifesustaining treatment plans and advance directives on lifesustaining treatment has increased after enactment of the LifeSustaining Treatment Decisions Act [9], and the present study found that life-sustaining treatment was often determined further in advance when the patient's condition deteriorated than was the case in previous studies. National health care systems and policies to ensure that patients at the end stage of life die peacefully are intended to guarantee the people's right to happiness. Through the rational implementation of the LifeSustaining Treatment Decisions Act, an environment in which appropriate medical judgment is applied and the patient's right to self-determination is respected should be created. In order to protect patients' dignity and value as human beings and to implement proper decisions on life-sustaining treatment, ongoing nationwide public awareness campaigns are needed, 
as well as appropriate judgment and detailed explanations from doctors about patients' conditions. In addition, studiesincluding regular periodic surveys-should be conducted to confirm the adequacy of these legal measures.

\section{CONFLICT OF INTEREST}

No potential conflict of interest relevant to this article was reported.

\section{SUPPLEMENTARY MATERIALS}

Supplementary materials can be found via https://doi. org/10.14475/kjhpc.2020.23.2.93.

\section{REFERENCES}

1. Yun YH. Hospice-palliative care and social strategies for improvement of the quality of end-of-life. J Korean Med Assoc 2009;52:880-5.

2. Kim M. The problems and the improvement plan of the hospice/palliative care and dying patient's decisions on life-sustaining treatment act. Korean J Hosp Palliat Care 2018;21:1-8.

3. Koh YK. Current status of end-of-life care in Korean hospitals. J Korean Med Assoc 2012;55:1171-7.

4. Kim JM, Baek SK, Kim SY, Maeng CH. Comparison of end-of-life care intensity between cancer and non-cancer patients: a single center experience. Korean J Hosp Palliat Care 2015;18:322-8.

5. Yoon SE, Nam EM, Lee SN. End-of-life care practice in dying patients with do-not-resuscitate order: a single center experience. Korean J Hosp Palliat Care 2018;21:51-7.

6. Tang ST, Liu TW, Lai MS, Liu LN, Chen CH. Concordance of preferences for end-of-life care between terminally ill cancer patients and their family caregivers in Taiwan. J Pain Symptom Manage 2005;30:510-8.

7. Holroyd EE. Chinese family obligations toward chronically ill elderly members: comparing caregivers in Beijing and Hong Kong. Qual Health Res 2003;13:302-18.

8. Koh YS, Heo DS, Yun YH, Moon JL, Park HW, Choung JT, et al. Charactersitics and issues of guideline to withdrawal of a life-sustaining therapy. J Korean Med Assoc 2011;54:747-57.

9. National Agency for Management of Life-sustaining Treatment [Internet]. Monthly statistics. Seoul: KoNIBP; 2019 [cited 2020 May 10]. Available from: https://www.lst.go.kr. 